\title{
Nevo Epidérmico Verrugoso Inflamatorio Lineal. A propósito de un caso Pediátrico.
}

Paula Yarmuch G' , Ximena Chaparro $\mathbf{R}^{1}$, Cecilia Fischer $\mathbf{S}^{1}$, Samuel Benveniste ${ }^{2}$, Viera Kaplan $Z^{3}$

'Unidad de Dermatología Infantil Hospital de niños Dr. Exequiel González Cortés (HEGC), Santiago de Chile; ${ }^{2}$ Servicio de Anatomía Patológica Hospital de niños Dr. Exequiel González Cortés (HEGC), Santiago de Chile; ${ }^{3}$ Interna de medicina, Universidad de Chile.

Adolescente sexo femenino de 13 años, sin antecedentes mórbidos personales ni familiares de importancia. Consulta por lesión pruriginosa en la zona inguinal derecha que aparece en los primeros meses de vida. Recibe corticoides tópicos en varias oportunidades en atención primaria sin respuesta. Al examen presenta placa lineal compuesta por múltiples pápulas escamosas rosadas confluentes con base eritematosa, resto de la piel, mucosas y uñas sanas, sin otros hallazgos patológicos. Se plantea diagnóstico de Nevus epidérmico Verrugoso Inflamatorio Lineal (NEVIL) que se confirma con biopsia de piel que muestra epidermis acantótica, áreas de paraqueratosis con agranulosis alternadas con otras de ortoqueratosis, hipergranulosis focal e infiltrado linfocítico en unión dermoepidérmica.

El NEVIL es un hamartoma cutáneo benigno. A pesar que la etiología y patogénesis son desconocidas se lo ha asociado con incrementos de IL1, IL 6, TNF $\alpha$ y molécula de adhesión tipo 1. Clínicamente suelen aparecer en la primera infancia como lesiones eritemato escamosas psoriasiformes de distribución lineal, que siguen las líneas de Blaschko, intensamente pruriginoso, más frecuente en el sexo femenino, unilateral y en extremidad inferior izquierda. Histológicamente destaca un patrón psoriasiforme: epidermis acantótica, áreas de paraqueratosis con agranulosis y otras con ortoqueratosis, hipergranulosis y capa de células córneas en canasta.

Algunos autores lo asocian con anomalías esqueléticas, retraso mental, convulsiones, alteraciones urogenitales, cardiovasculares y oculares, constituyendo el Síndrome del Nevo Epidérmico o Síndrome Solomon. El diagnóstico diferencial con la psoriasis lineal en ocasiones es muy dificultoso, en estos casos la inmunohistoquímica puede ser de utilidad.

Su manejo es complejo, ya que suele ser refractario a la terapia médica y presenta frecuentes recurrencias post-quirúrgicas. Otros tratamientos reportados incluyen el 5 fluorouracilo, esteroides tópicos e intralesionales, ácido tricloroacético, podofili- no, retinoides, crioterapia, electrocoagulación, dermoabrasión, terapia fotodinámica y láser ablativo.

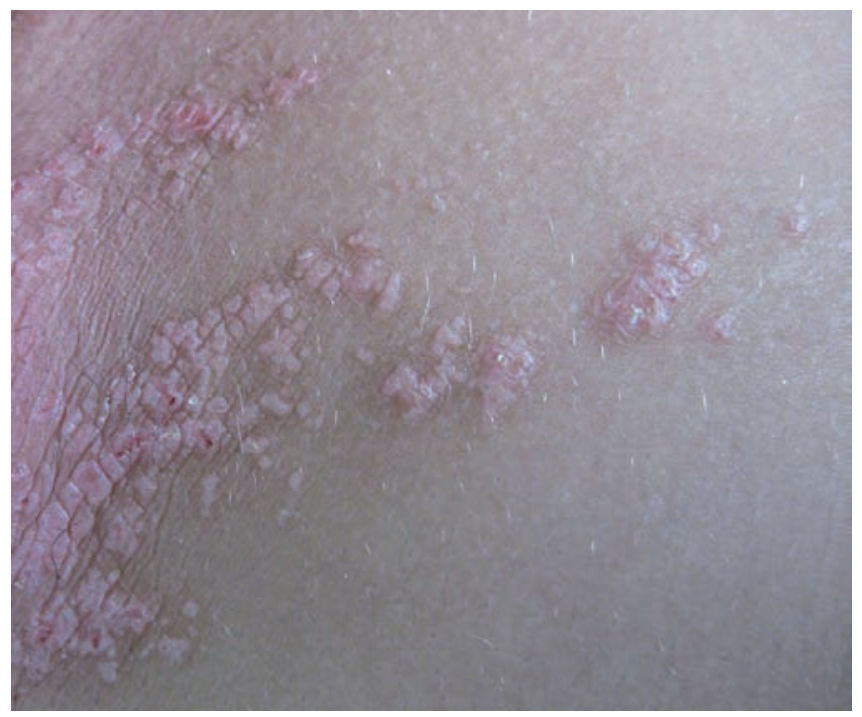

\section{Referencias bibliográficas}

- Kumar CA, Yeluri G, Raghav N. Inflammatory linear verrucous epidermal nevus syndrome with its polymorphic presentation - A rare case report. Contemp Clin Dent. 2012;3(1):119-122.

- Kim R, Marmon S, Kaplan J, Kamino H, Pomeranz MK. Verrucous epidermal nevus. Dermatol Online J. 2013;19(12):20707 